\title{
The Sustainable Aging Health Network in Thailand
}

\author{
Thitima Wataneeyawech ${ }^{1, *}$, and Patcharuch Onto $^{2}$ \\ ${ }^{1,2}$ Health Science Department, Nakhon Sawan Rajabhat University, Thailand.
}

\begin{abstract}
The objectives of this research were to explore factors related to aging health network and to identify the sustainable aging health network in a community of Thailand. The research design was mixed method that included both qualitative and quantitative research design. The samples were aging people and aging health networks in community. The instruments were the health services network interview form and aging health factors related questionnaire. The data were collected include demographic data, health status, health service for aging. The finding shown that the factors related of aging health were aging age, aging health assessment, aging health security, health examination, aging health care, aging health information,aging health service,aging health activities, and health services barriers. The sustainable aging health network in Thailand depended on community organization related aging health network as follow: 1) District and subdistrict administrative organization 2) Health organzation: Health Promoting Hospital 3)Academic organization :University and educational institute in community. The data from interview from found that the ways to develop sustainable aging health network should have participation of every sectors from all health services network in community of Thailand.
\end{abstract}

\section{Introduction}

A large amount of aging people is increasing all over the world. The incresing statistics is trending into aging society. The aging population was at highest level and predicts the rate of ageing population in the $21^{\text {st }}$ century will exceed that of the previous century. The aged people over 60 years had over tripled since 1950, reached 700 million in 2006 and will reach 2 billion by 2050 . With the medical technology development, Aging people tend to live longer, and will encouraging with health problems and disabilities. They will meet one or more health problems even slightly and severe health problems. More than a half of aging has diseases or chronic illness that effective and sustainable longterm aging health care in their community. (The World Health Organization (WHO), 2018). [1]

In Thailand, the aging population is also increasing to neary 20 persent of all population in Thailand and the absolutely aging society will came to Thailand in 2030. The aspect of individual, family and communty levels, the sustainable aging health network in Thailand is important and need to develop to support aging society. Active aging can work for themself, family and community. Some of them raise grandchildren, who volunteer their time in the community, and who are able to meaningfully share their culture and values with younger generations. (Helpage global network, 2019). [2] Thailand has start some challenging process to support an ageing society. Significant challenges remain largely due to the rapidity of the demographic ageing in Thailand, including work and education opportunities for older adults, long-term care plans for older people and establishing age-friendly housing but existing laws and policies on ageing are not always put into practice. Aging people were facing with health problems both physical, mental health and aslo socioeconomic problem too.

\footnotetext{
* Corresponding author:Thitima_2006@hotmail.com
} 
Aging is also characterized by the emergence of several complex health states that tend to occur only later in life and that do not fall into discrete disease categories. The common conditions in older age include hearing loss, cataracts and refractive errors, back and neck pain and osteoarthritis, chronic obstructive pulmonary disease, diabetes, depression, and dementia. Furthermore, as people age, they are more likely to experience several conditions at the same time. These are commonly called geriatric syndromes. They are often the consequence of multiple underlying factors and include frailty, urinary incontinence, falls, delirium and pressure ulcers. All these health problem are impact aging quality of life and sustainable health in aging.

Aging society will impact aged person themself and also aging health network. If Thaistakeholder did not prepare appropriated support for developing area in the country. There are various strategies to develop older adults in Thailand such as The 12th National Socioeconomic Plan emphasized on humankind and society development in knowledge and learning followed by the King Bhumipol Initiative that stressed on sufficiency health to create healthy, good health services, good society, and happiness. The aging act (2003) protected, promote, and support older adults related with the strategic planning to prepare aging society in Thailand. The 2 nd National Elderly Plan (2002-2021) emphasized on integrated aging care, especially in knowledge processing and developing about aging. Ministry of Public health supported the research and development in public health and promoted good health behaviors and health promotion. (The Health Security Organization. 2010). [3]

The Sustainable Aging health Network in Thailand was need to be explored to solve the problems that how to manage with factors related to aging health network. The objectives of the research were to explore factors related to aging health network and to identify the sustainable aging health network in a community of Thailand. The sustainable aging health network is an essential part of personnel and organization related to aging to work together and make the best effective in aging health care.

\section{Review Literature}

The research of sustainable aging health network in Thailand was one of the main strategy to solve the aging health problem in Thailand. The literature reviews was about aging, sustainable health care, and aging health network.

\subsection{Aging}

A large amount of aging people in the world is quickly increasing all over worldwide. The baby boom generation in the United States and Europe joining the older ranks in recent years and with the accelerated growth of older populations in Asia and Latin America, the next 10 years will witness an increase of about 236 million people aged 65 and older throughout the world. Thereafter, from 2025 to 2050. The aging population are also living longer. By 2050, the world's population aged 60 years and older are increasing up from 900 million in 2015 to total 2 billion. Today, 125 million people are aged 80 years or older. By 2050, there will be almost this many (120 million) living in China alone, and 434 million people in this age group worldwide. By $2050,80 \%$ of all older people will live in low- and middle-income countries. (The World Health Organization (WHO), 2018). [1]

Thailand aging population tend to increase everyyear. One aging individually came in the last stage of life, which follows after adulthood and that precedes the death of the person. Because it is precisely during this phase that the body and the cognitive faculties of the people will deteriorate. (Martin L. G., Schoeni R. F., and Andreski P. M. 2010) [5] Usually described as elderly people exceeding 60 years of age. From Aging Act (2003) confirm that aging in Thailand was a person whose age more than 60 years old. The aging population is define differntly in each country, In Thailand, define aging is people in aged of 60 and over. (Aging act in Thailand, 2003) [4] 
The deteriorate signs in aging as the common health conditions associated with ageing include hearing loss, cataracts and refractive errors, back and neck pain and osteoarthritis, chronic obstructive pulmonary disease, diabetes, depression, and dementia. Furthermore, as people age, they are more likely to experience several conditions at the same time. Symptoms of Aging may change in different rates to different degrees and many common effects of aging. Some common signs and symptoms of aging include:Increased susceptibility to infection, Greater risk of heat stroke or hypothermia, Slight decrease in height as the bones of our spines get thinner and lose some height, Bones break more easily, Joint changes, ranging from minor stiffness to severe arthritis, Stooped posture, Slowed and limited movement, Decrease in overall energy, constipation, urinary incontinence, slowing of thought, memory, and thinking, reduced reflexes and balance, decrease in visual acuity, hearing loss, Wrinkling and sagging skin, Whitening or graying of hair, weight loss, after age 55 in men and after age 65 in women, in part due to loss of muscle tissue. [6] Aging age was characterized by many complex health status that tend to occur only later in life and that do not fall into discrete diseases and leading to the consequence of multiple underlying factors Many countries have developed geriatric medicine as a speciality, they are often overlooked in traditionally structured health services and in epidemiological research. [1]

\subsection{Sustainable health care}

The concept of sustainable Development Goals (SDGs) is trendy to use in many countrys. In the otherwise, it was known as the Global Goals, a set of objectives within a universal agreement to end poverty, protect all that makes the planet habitable, and ensure that all people enjoy peace and prosperity, now and in the future. The Sustainable Development Goals (SDGs) are a set of global goals for fair and sustainable health at every level: from planetary biosphere to local community. The aim is to end poverty, protect the planet and ensure that all people enjoy peace and prosperity, now and in the future. The goals provide a well consulted framework that is sufficiently scientifically robust, politically acceptable, and publicly intuitive. The goals provide us with our best chance of ensuring the necessary collaboration and alignment as we implement global approaches to securing a fair, healthy and prosperous future for ourselves, our children and grandchildren. Although the 17 goals in five 'areas of critical importance'; sometimes known as the 5 'P's, these are People, Planet, Prosperity, Peace and Partnerships [7]

The concept of sustainability is increasingly discredited as a useful concept by itself, it appears to be serving some purpose when preceded by a delineating modifier like ecological or agricultural or economic. (John Morelli, 2011)[8].The ecological sustainability as a conservation concept advance an ecological definition of sustainability that connects human needs and ecosystem services. Social sustainability towards some definitions is a positive condition within communities, and a process within communities that can achieve that condition. Economic sustainability should involve analysis to minimize the social costs of meeting standards for protecting environmental assets but not for determining what those standards should be. Health aspect of sustainability was very new but it need to explore to develop the sustainable aging health network in Thailand. The sustainable aging health not only include in economy aspect but include many related factors: social, environmental and quality of life.

Barbier, E.B. (1987) revealed the sustainable development in a concept of sustainability that both distinguishes from other post-war meanings of development and is useful for practical analysis and policymaking. [9] In theory the economy exists to support society and enhance human well-being. It is the system within a society where limited resources are managed fairly and sustainably. The ultimate goal of economics is to improve the living conditions of people in their everyday life. Sustainability maintains the health and biocapacity of the environment. Sustainability supports the well-being of individuals and communities. Sustainability promotes a better economy where there is little waste and pollution, fewer emissions, more jobs, and a better distribution of wealth. The sustainability is when all people individuals, societies, nations live within the limits of the Earth's biocapacity. [10]. 
The ultimate goal of development today has shifted from that of economic growth to improvement of human well-being because the majority of the world's populations still suffer from lacking of basic necessities in life. The need of people including food, shelter, education and healthcare. Though poverty is one of the causes of low quality of life, improving human well-being does not involve merely monetary value. The ability of people to make their own choices is also vital. The Philosophy of Sufficiency Economy (PhilSE) treats this problem at a very fundamental level by focusing on the idea that individuals and families should be able to rely on themselves as the most important part of the development. In order to achieve selfreliance condition, the PhilSE offers three basic principles which are moderation, reasonableness and self-immunity [11,12] The most famous concept of sustainablility in Sustainable economy of His Majesty, King RAMA $9^{\text {th }}$ that explained that Sufficiency Economy differs from the English term and idea of "self-sufficiency" that. "Self-sufficiency means producing enough for one's own need, can standing on their own way. The Sufficiency Economy concept is much broader mening that was "Sufficiency is moderation". If one is moderate their desires they will have less need than others. (Anawat Bunnag, 2013) [13] Many factors influencing healthy ageing such as their personal characteristics such as their sex, ethnicity, or socioeconomic status due to people's physical and social environments including their homes, neighbourhoods, and communities were need to explore.

\subsection{Aging health Network in Thailand}

The increasing of aging population was challange problems to the government of Thailand. Many organization working related to aging health tend to alert in this problem. Actual situation is they work seperatedly in their duty and criteria. Their were no central health organization to co-work together. The responsibility for policy will always rest with governments, but the changing face of public health will require new ways of working. WHO created new forms of partnership and building effective coalitions; at the regional level, carrying out and commissioning analysis and research that provides policy-makers with the information they need to make their case; and, at country level, a widening network of relationships across government, civil society and academia.

\section{Research Framework}

The research framework of The Sustainable economy on Aging health Network framework included the concept of factors related aging health and aging health network.

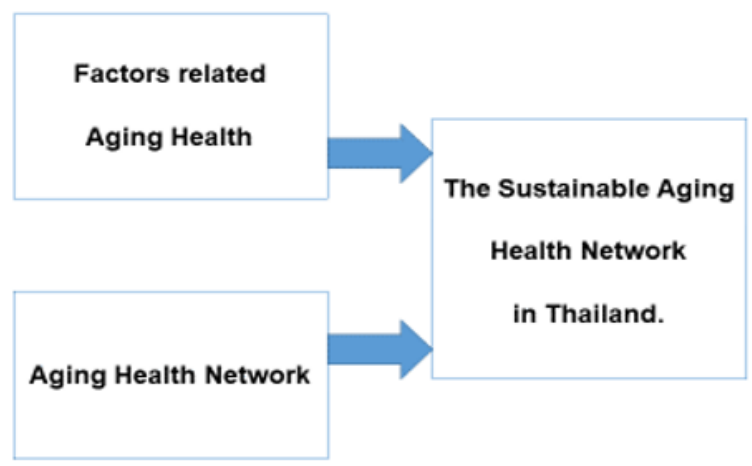

Research Framework of The Sustainable Aging health Network in Thailand

Fig. 1. Research framework of The Sustainable economy on Aging health Network framework 


\section{Research method}

The research design was mixed method that used both quantitative and qualitative research design. The methodology were using descriptive data from survey and interview.

\subsection{Populaton and samples}

The population were aging people in a community and personnel in health care network. The samples were 50 aging people who aged more than 60 years olds selected by multistage random sampling and 3 personnel of health care network in Nakhon Sawan Province, Thailand.

\subsection{Data collection and Analysis}

There were 2 instruments in this research. The first, The Aging Health Questionairre was the demographic data and factors related to aging health. It pass the content validity was at .78 and the Cronbach's alpha reliability coefficient were at .83 . The second instrument was in-depth interview record form. The data were collected and analysis by statistical computer program. The quantitative data were analysis by computer program such as frequency, percentage. The qualitative data were analyzed by using content analysis.

\section{Research findings}

The finding of the sustainable aging health network in Thailand was reveal in two aspects: factors related to aging health and health care network in Thailand.

\subsection{Factors related to aging health}

The factors related to aging health were aging age, aging health assessment, aging health security, aging health examination, aging health care, aging health information, aging health service, aging health activities, and health services barriers were shown as follow:

Aging age were at 61-69 years old at 60\%, follow in aged between 70-79 years old at $28 \%$ and $12 \%$ were older than 80 years old. Aging health assessment by themselves were mostly at good level 56\%, Moderate level at $26 \%$, and very good level at $18 \%$. Aging health security mostly in the universal coverage (UC.) health system at $62 \%$, government enterprise officer system at $30 \%$, and Social security scheme system and others health insurance at $8 \%$. Aging who get yearly completed health examination of aging only $8 \%$ and incomplete health examination at $92 \%$. Aging health care when they were sick, they usually went to government hospital at $55.1 \%$, buy drug by themselves at $24.6 \%$, Doctor private clinic $11.6 \%$, family care at $2.9 \%$ and same as go to private hospital at $2.9 \%$.

Aging Health Information came from television media at $51.3 \%$, from health care personal at $16.3 \%$, paper media such as booklets, brochore, leaflets at $13.2 \%$, radio media at $7.4 \%$, boardcasting tower at $7.4 \%$ and internet media at only $4.4 \%$. Aging Health Service need fast tract to see doctor at $35.8 \%$, need quality drugs at $35.8 \%$, need enough visiting area at $16.4 \%$ aging clinic at $6.0 \%$ and effective medical personal at $6.0 \%$. Aging Health Activities in community reported many activitiec for aging such as: the activities about exercise in community at $51.4 \%$, health education at $18.6 \%$, monthly examination at $17.2 \%$, and included aging club and aging school were at $12.8 \%$. Health Services Barriers of aging were the problem about the early morning to get on queue at $53.3 \%$, Long distance from home at $20.0 \%$, Nobody who bring aging to hospital at $15.0 \%$, and travel expense cost to hospital at $11.7 \%$. The barriers of health care services were the interestion points for health care personnel and organization to take care anf slove the problems. 
Table 1. Factors related to aging health

\begin{tabular}{|c|c|c|c|}
\hline Age of aging & Percentage & Aging Health Assessment & Percentage \\
\hline \multirow{2}{*}{$61-69$ years old } & \multirow{2}{*}{60} & Very good & 18 \\
\hline & & Good & 56 \\
\hline \multirow{2}{*}{$70-79$ years old } & \multirow{2}{*}{28} & Moderated & 26 \\
\hline & & Poor & 0 \\
\hline Older than 80 years old & 12 & Very poor & 0 \\
\hline Aging Health security & Percentage & Aging Health Examination & Percentage \\
\hline $\begin{array}{l}\text { Universal health coverage } \\
\text { system }\end{array}$ & 62 & $\begin{array}{l}\text { Completed Health } \\
\text { Examination }\end{array}$ & 8 \\
\hline $\begin{array}{l}\text { Government enterprise } \\
\text { officer system }\end{array}$ & 30 & $\begin{array}{l}\text { Incomplete Health } \\
\text { Examination }\end{array}$ & 92 \\
\hline $\begin{array}{l}\text { Social security scheme } \\
\text { system and others health } \\
\text { insurance }\end{array}$ & 8 & & \\
\hline \multicolumn{3}{|c|}{ Aging Health Services Barriers } & Percentage \\
\hline \multicolumn{3}{|c|}{ Early morning to get on queue } & 53.3 \\
\hline \multicolumn{3}{|c|}{ Long distance from home } & 20.0 \\
\hline \multicolumn{3}{|c|}{ Travel expense cost to hospital } & 11.7 \\
\hline \multicolumn{3}{|c|}{ Nobody who bring aging to hospital } & 15.0 \\
\hline
\end{tabular}

\subsection{Aging Health care network in Thailand.}

The research of sustainable aging health network in Thailand was interview key imformants in a community and found that their were many organization from many Ministry who work for aging. Each Ministry had their own criterias, the officers from each secter did only the work on their duty. The Ministry of Public Health work on health care service, The Ministry of education work on life long education, Ministry of Social Development and Human Security work on aging and disability person, Ministry of Interior work on community support and aging allowance. The problems on aging health care network found that :

1) The separation of working in each sectors. When aging had their problem, they had to go to connect each office by themselves.

2) Lack of intregrated information for aging.

3) Few professional health support for disability aging in community.

4) Slight fund support that solve need of aging.

The necessary of aging health care network is to set up participatory of aging health care network in community, build the connection of health care networking together. The main organization found in aging health care network were :

1) District and subdistrict administrative organization

2) Health organzation : Health Promoting Hospital

3) Academic organization: University and educational institute. In order to develop the sustainable aging health network should be integated personnel, funding, and overlap working all together that will set the effective sustainable aging health network in community. 


\section{Conclusion and Discussion}

The sustainable of aging health care network in a community of Thailand Health shown two aspects: 1) Factors related to aging health and 2) Health care network in Thailand. Aging age were mostly at 61-69 years old at $60 \%$ and only $12 \%$ were older than 80 years old that mean the aged generation was at the beginning. More than half of aging assessment themselves were at good level $56 \%$ and moderated level at $26 \%$ that mean they still feel active. Aging health security was in universal coverage in health system $62 \%$ follow with government enterprise officer and Social security scheme system that mean all of them had health security support. Yearly completed health examination of aging only $8 \%$ may be the next problem in health care services because screening before disease were need to early detect and get the patient to cure. Aging health care shown that aging had many chances to access to treat when they sickdepend on their health right such as government hospital. Aging Health Information came from television media, paper, radio, boardcasting tower in community. Health information from health care personal directly still also need for some aging, but internet media was only at $4.4 \%$ that need to be support in the future. Aging Health Service need fast tract to see doctor, quality drugs were the two most need in this topic follow with physically hospital environment supports: space area, effective services, and special clinic for aging.

To create the sustainable of aging health care network was to solve the problems of the separation of working in each sector, lack of intregrated information, few professional health support and low funding support. The participatory of aging health care network in community is necessary to build the connection of health care networking together both District and subdistrict administrative organization, Health organzation, and Academic organization. From The information from Consultation on Global Strategy and Action Plan on Ageing and Health (2019). [2] stressed that : 1) Commitment to Healthy Ageing. 2) Aligning health systems with the needs of older populations. Health systems need to be better organized around older people's needs and preferences, designed to enhance aging intrinsic capacity, and integrated across settings and health care providers. 3) Developing systems for long-term care. 4) Creating agefriendly environments. This will require actions to support healthy ageing in all policies and at all levels of government. These activities build on and complement WHO's work to develop age-friendly cities and communities including the development of the Global Network of Age Friendly Cities and Communities and an interactive information sharing platform Age-friendly World. 5) Improving measurement, monitoring and understanding.

In order to cope with the challenges of an aging population, policies and services promote keeping elders in the community and letting them age in place rather than sending them to specialized institutions. Aging in place refers to the option where people can stay in their homes as they age. This policy option, however, poses various challenges and may also threaten the quality of life of the aging. The literature review performed on the quality of life of older people aging in place to determine whether the actual assessment of quality of life can be used within aging in place. [20]

Government policies related to aging in United Nations Assembly recognized aging rights with respect to autonomy, involvement, care, self-satisfaction and esteem, Thailand established the "National Committee of Senior Citizens." The government's current policies and programs are in line with the Second National Plan for Older Person (2002-2021). This plan focused on the development of policies and programs to support older persons. Some successful program activities are highlighted: 1) Promoting a positive attitude toward elderly persons 2) Promoting health for the elderly 3) Social protection for the elderly. [2] The policy framework from International Council on Active Aging (2021) was intended to inform discussion and the formulation of action plans that promote healthy and active ageing. The main sections of the publication are 1) Global ageing: a triumph and a challenge 2) Active ageing: the concept and rationale 3) The determinants of active ageing: understanding the evidence 4) Challenges of an ageing population and 5) The policy response. [15] 
The National Strategy for 2018-2037 was created in Thailand to prepare for an aging population focuses on human resource development and social equality development. The Act on Older Persons was revised in 2010, and the comprehensive ageing policy aims to improve quality and equality of education, promote savings and creating good practice in elderly orientated communities. The aim of the National strategy is to prepare for an aging society, across social, health and living. The Act on Older Persons also aims to promote healthy living, access to healthcare and long-term community-based care. As well as promoting pre-aging healthy behaviours and increasing awareness of health risk factors and training more age friendly health care professionals. The new Act aims to ensure that income security in old age is guaranteed as a basic human right, and to strengthen the old age pension system through: 1) Improved coordination and integration of the different existing old age pension schemes 2) Establishment of a national body to develop an overall old age pension policy and to regulate 3 ) Modification of the current Old Age Allowance to be a universal basic pension scheme with an improved benefit level. Coordinated by the civil society network core group, the new Act will be publicised to and shared with CSO networks across the country in order to secure public support that will be immensely important for the new Act's approval. [2]

The discussion of the research finding, from the data of aging age were at 61-69 years old, 70-79 years old. The trending age of aging in concequence to the statistic of population that is strat to increas in each genertion. Aging health assessment by themselves were mostly at good level, Moderated, and very good consequencely. The study of the ability to help themselves and depression of the ageing found that ageing had good mental conditions and help themselves as normal basic movement, 2/3 of them lived with families and 1/3 lived alone, and necessary to consider on the condition of sex, living status and health condition.[16] Our research finding support the question that aging health condition was found that aging assessed their health were mostly at good level that can promote aging to stay healthy with good mental health and also good ADLs. The aging in community are mostly active aging that they still stay in younger old age, can do their daily life individually, the socioeconomic status and health were assess in good and moderate level. But need to assess more factor details according to fully engaging in life. From International Council on Active Aging (2021) were seven dimensions of wellness: 1) emotional, 2) environmental, 3) intellectual/cognitive, 4) physical, 5) professional/vocational, 6) social and 7) spiritual. [15]

In Thailand, health security were mainly seperated in to 3 section. Some of them were government enterprise officer and Social security scheme system after retired (older tham 60 years old). Aging health care when they were sick they usually went to government hospital because they had to follow their right and health criteria in UC services. Some of them buy drug/care in family, or went to docter private clinic or private hospital in lower percent because they had to paid all very expensive cost by themself but if they use their health care right in the correct place they had not to paid for the treatment cost. Aging Health Service, aging need fast tract to see doctor at $35.8 \%$, need quality drugs at $35.8 \%$, need enough visiting area at $16.4 \%$ aging clinic at $6.0 \%$ and effective medical personal at $6.0 \%$. These findings were support the situation of hospital care in Thailand. Healthcare Healing Environment Design (HHED) reported problems about hospital environment were the color, furnitures, light, air ventrilation, air quality,hot, bad odor, hudidity and surrounding environment that were not support good quality of services. [17] The determinants related to health and social service system were the related factors to sustainable aging health network such as health promotion and disease prevention, curative services, long-term care, mental health services, tobacco, use physical activity, healthy eating, oral health, alcohol, and medications. 
To promote active ageing, health systems need to take a life course perspective that focuses on health promotion, disease prevention and equitable access to quality primary health care and long-term care. [18] Aging Health Information came from television media, Health care personal, paper media, radio, broadcasting tower and internet media at only 4.4\%. Aging in Thailand mostly get health imfromation from television media bacause the baby boom generation were grown up from this device. Very few of them used internet media. From the study of Usak M, Kubiatko M, Shabbir MS, Viktorovna Dudnik O, Jermsittiparsert K, Rajabion L. about Health care service delivery based on the Internet of things [19] shown that the Internet of Things (IoT) becomes a heterogeneous and highly distributed structure which can respond to the daily needs of people. There has been increasing attention in the integration of IoT and health care both in academic and the business world. The researh was directly support academics and working professionals for better knowing the progress in IoT mechanisms, and could help the governments to improve health services in society and commercial interactions. The support of IoT for aging in present and next generation was need for aging to search nasessary health information, to connect to family and friends far away, to call for health care services for counselling, for help in emergency situations.

Aging Health Activities were the activities about exercise in community at 51.4\%, health education at $18.6 \%$, monthly examination at $17.2 \%$, and included aging club and aging school were at $12.8 \%$. Aging Health Activities in community could make physical and mental support for aging. The Social support were also important factors in aging health. Inadequate social support is associated not only with an increase in mortality, morbidity and psychological distress but a decrease in overall general health and well being. [18] The aging activities were need to set up consistency in community to promote health such as various exercises, cultural activities, health examination. Some community were integrated many activity in a convenience occasion. As well as the concept of "aging-in-place." was presents as aging in community and long-term care rely heavily on financial capital and expensive professional services. This concept encourages a proactive strategy to create supportive neighborhoods, networks, well-being and quality of life for aging at home in community. [20]

Health Services Barriers of aging were the problem about the early morning to get on queue at $53.3 \%$, Long distance from home at $20.0 \%$, Nobody who bring aging to hospital at $15.0 \%$, and travel expense cost to hospital at $11.7 \%$ This finding were from World Health Organization. (2002) [18] about the factors related to physical environment of aging is an imporant factors such as age friendly physical environments in independence and dependence aging. When aging grown older, they were facing to multiple physical barriers of doing things, decreasing the capacity of daily living. Urbanization and the migration of younger people for jobs may leave aging isolated in rural areas with little means of support and little or no access to health and social services. Especially, aging who live alone were isolation, feeling of depression, reduced fitness and increased mobility problems. The research of the overcoming barriers to health service access shown the barriers are likely to be more important such as the costs of access, lack of information and cultural barriers. Demand barriers present in low- and middleincome countries and evidence on the effectiveness of interventions to overcome these obstacles. [21] The renewed commitment to primary health care presents an opportunity to strengthen health systems in West and Central Africa. People living in rural areas or from poor families identified severe or very severe factors were related to health financing, essential medical technology and products, integrated health service delivery, and community ownership and partnerships. [22] From the research of characteristics of elderly home care volunteers in Western of Thailand found the similarity of factors related to aging but difference in obstacles in aging home care volunteer. The problems about the participation with local government organizations is not high and there is a lack of participation from the elders may occured in aging home care but differ from the setting in community that many sectors try to help aging to stay healthy in their community. [20] 
Many factors related to promote sustainable aging health care network were explore in this research but they still had more factors interesting to study next. From the research finding of Sheboygan County (2021) shown some interesting factors [19] as follow: 1) Person: family members, caregivers, community leaders, health volunteers, and community health network. 2) Government and non-government network: community, government and non-government network, 3) Local Administration Organization, support by house, temple, and school. 4) Health status and ADL: Good ADL, can go outside not only stay in house or in bed 5) Health dimensions: Physical, Mental, Social, and Spiritual 6) Aging: Only self-reliance and Can help others. To set the sustainable of aging health care network in a community of Thailand were many network came from many Ministry. The problems on aging health care network were the separation of working in each sectors, Lack of intregrated information, few professional health support and low funding support. The participatory of aging health care network in community is necessary to build the connection of health care networking together both District and subdistrict administrative organization, Health organzation, and Academic organization.

\section{Acknowledgements}

Thanks Research and Development Institude, Nakhon Sawan Rajabhat University for research funding. Thanks Faculty of Science and Technology, research team, anyone related, and family support to work hard for this research.

\section{Further research}

This research findings were a part of the total research. The next step is to study relationship and connection to manage health network for aging and to develop sging quality of life, aging community health care activities, health assessment, health education.

\section{References}

1. WHO. Aging and Health. (2018).

2. HelpAge. Ageing population in Thailand. (2019).

3. HSO. Health Information. (2010).

4. SDHS. Thailand Aging Act 2003. (2003).

5. L. Martin, R. Schoeni, and P. Andreski. Demography, 47 (2010).

6. Drug.com. Aging (2021).

7. S. Morton, D. Pencheon, N. Squires. BMB, 124 (2021).

8. J. Morelli J. JES, 1(2011).

9. E. Barbier. Environmental Conservation, 14(1987).

10. Econation for people planet. Sustainable economy. (2021).

11. B. Supadhiloke. Proc. International Conference, 2010.

12. S. Kantabutra. Sustainable. (2021).

13. A. Bunnag., IJSSH, 3 (2013).

14. WHO. A Healthier South-East Asia. (2018).

15. ICAA. What is active aging?. (2021).

16. M. Rugbumrung, J. Dibyamandala, C. Mangkhang, K. Kamsiripiman. IJCLSI, 7(2020).

17. HHED. Open environment problem in hospital. Hfocus. (2016).

18. WHO. The Second United Nations World Assembly on Ageing, Madrid, Spain. (2002).

19. M. Usak, M. Kubiatko, M. Shabbir, D. Viktorovna, K. Jermsittiparsert, L. Rajabion. IJCS, e4179. (2019).

20. P.Whangmahaporn. IJCLSI, 11 (2019).

21. T. Ensor, S. Cooper. HPP, 19 (2004).

22. A. Simen-Kapeu, M.E. Reserva, R.E. Ekpini. GHSP, 16 (2021) 
23. C. Sheboygan. Are there any resources to support family caregivers?. (2021).

24. P. Vanleerberghe, N. Witte, C. Claes, R. Schalock, D. Verté. QLR, 26 (2017) 